\title{
Avaliação endócrina e morfológica de transplante ovariano homógeno
}

\author{
Endocrine and morphological assessment of ovarian homologous transplantation
}

Andy Petroianu'; Luiz Ronaldo Alberti²; Leonardo de Souza Vasconcellos ${ }^{3}$; Juliana Moysés Leite ${ }^{4}$; Lúcia Porto Fonseca de Castro ${ }^{5}$

\section{unitermos resumo}

Hormônios ovarianos

Introdução: A insuficiência ovariana decorre de ooforectomia bilateral em diversas afecções do ovário,

Transplante de ovário como neoplasia e sepse, além de quimioterapia, radiação pélvica e fatores relacionados à idade. Suas Histologia ovariana Coelhos complicações sistêmicas, como insuficiências hormonais, podem ser de difícil controle. Objetivos: Avaliar aspectos endócrinos e histológicos ovarianos após seu transplante ortotópico, sem anastomose vascular e submetidos à imunossupressão pela ciclosporina. Material e método: Foram utilizadas 12 coelhas da raça Nova Zelândia Branca $(n=6)$ e Califórnia $(n=6)$, divididas em dois grupos: grupo $1(n=4)$, de controle, submetido apenas a laparotomia, sem outro procedimento cirúrgico; e grupo $2(n=8)$, submetido a ooforectomia bilateral e transplante ortotópico dos ovários, que foram trocados entre as duas raças de animais. De um lado, foi transplantado o ovário íntegro e, do outro, o ovário fatiado. Não houve anastomose vascular. As coelhas foram imunossuprimidas com ciclosporina (10 mg/kg ao dia). No final do período de acompanhamento de seis meses, foram feitas dosagens de estradiol, progesterona, hormônio foliculoestimulante (FSH) e hormônio luteinizante (LH), além de estudo histológico de ovários, tuba uterina e útero. Resultados: Os ovários transplantados estavam rodeados por tecido conjuntivo, bem vascularizados, mostrando folículos em diferentes estádios de desenvolvimento. A histologia tubária e uterina também foi preservada em ambos os grupos. A dosagem hormonal foi normal em todas as coelhas, indicando que, do ponto de vista endócrino, o ovário transplantado estava funcionando. $\mathrm{O}$ transplante ovariano homógeno ortotópico, sem pedículo vascular e submetido à imunossupressão pela ciclosporina, foi eficaz para a manutenção de hormônios ovarianos em níveis normais.

\section{abstract}

Introduction: Ovarian failure may be due to bilateral oophorectomy on several ovarian diseases, such as infection and neoplasm; chemo and radiotherapy as well as factors related to age led to endocrine disturbances followed by systemic complications. Objectives: To assess endocrine and histological ovarian aspects following allogeneic ovarian transplantation without vascular pedicle and immunosupressed by cyclosporine. Material and method: Twelve female New Zealand White and California rabbits were divided into 2 Groups: group $1(\mathrm{n}=4)$, sham operation; and group $2(\mathrm{n}=8)$, submitted to a laparotomy and ovarian bilateral transplantation between pairs of animals. In one side the ovary was intact and in the other side the ovary was sliced. At the end of the followup period, blood samples were studied for estradiol, progesterone, FSH and LH. At the end of the experiment, histological studies of ovaries, uterus and tubes were carried out. Results: The ovary implants were surrounded by connective tissue; they were well vascularized, and presented follicles in different stages of development. Hormonal values were normal in all rabbits. Conclusions: Allogeneic orthotopic ovarian transplantation without vascular pedicle and immunosupressed by cyclosporine was effective to preserve normal level of ovarian hormone.

\section{key words} Ovarian hormones Ovary transplantation Ovarian histology Rabbits Cyclosporine

\footnotetext{
1. Professor-titular do Departamento de Cirurgia da Faculdade de Medicina da Universidade Federal de Minas Cerais (UFMG); livre-docente da Faculdade de Medicina de Ribeirão Preto da Universidade de São Paulo (USP); livre-docente da Escola Paulista de Medicina da Universidade Federal do Estado de São Paulo (EPM/Unifesp); doutor em Fisiologia e Farmacologia; pesquisador 1A do Conselho Nacional de Desenvolvimento Científico e Tecnológico (CNPq).

2. Médico-residente de Cirurgia Ceral do Hospital Júlia Kubitschek de Belo Horizonte.

3. Médico-residente de Patologia Clínica e Medicina Laboratorial do Hospital das Clínicas de Minas Cerais.

4. Médico-residente de Cinecologia e Obstetrícia do Hospital Mater Dei de Belo Horizonte.

5. Anatomopatologista; mestre em Patologia Ceral; docente na Faculdade de Medicina da UFMG

Auxilio financeiro: Fundação de Amparo à Pesquisa do Estado de Minas Cerais (Fapemig) e CNPq.
} 


\section{Introdução}

Muitas pacientes com câncer sofrem perda iatrogênica da função ovariana, mesmo sem o ovário estar envolvido na doença, em decorrência de tratamento radioterápico e quimioterápico ${ }^{(11,12)}$. Em outros casos, a ooforectomia é realizada através de procedimentos sobre a pelve, mesmo não havendo inconveniência em sua manutenção. Essa conduta resulta em menopausa precoce e distúrbios funcionais, como disfunção sexual e níveis alterados de lipoproteínas, além de maior risco de osteoporose e doenças cardíacas $(11,12,19,22)$.

$\mathrm{Na}$ ausência de doença auto-imune, uma alternativa fisiológica para a manutenção da função hormonal em mulheres que precisam se submeter à retirada de ovários normais, nas quais a função regulatória do eixo hipotálamohipófisário está intacta, é o transplante ovariano. Diversas técnicas experimentais de auto-implante ovariano vêm sendo pesquisadas ${ }^{(2,5)}$. A multiplicidade de espécies animais e de métodos estudados para a conservação da função ovariana resulta em informações conflitantes quanto à eficácia da preservação hormonal ${ }^{(18,21,23)}$.

A utilização de tecidos ovarianos criopreservados e reimplantados em posição heterotópica é uma alternativa mais fisiológica para que se mantenha a função hormonal no pós-operatório tardio da retirada de ovários normais $^{(1,15,23,24)}$. A maioria dos estudos sobre preservação de tecido ovariano restringe-se aos transplantes autógenos. Os homógenos ortotópicos ou heterotópicos, até o momento, foram pouco investigados, principalmente devido às dificuldades de imunossupressão(10).

A ciclosporina (CyA) é um peptídeo derivado de fungos utilizado no tratamento de pacientes submetidos a transplantes de órgãos. Sua atividade imunossupressora baseia-se na inibição da resposta imune celular e na diminuição da produção de linfócitos $T$ dependentes de anticorpos ${ }^{(6)}$. Por outro lado, verificou-se que a CyA provoca disfunções no sistema endócrino ${ }^{(21)}$, tendo sido descritas alterações na função gonadal de ratos e humanos $^{(18,21)}$. Esse efeito é, provavelmente, devido à interação entre a CyA e a prolactina (PRL) sobre o mesmo receptor linfocítico em ratos $^{(6)}$.

O objetivo do presente trabalho foi avaliar a possibilidade de se manter a função endócrina ovariana após ooforectomia total bilateral por meio de transplante heterógeno de ovário, em posição ortotópica e sem anastomose vascular, em animal imunodeprimido por ciclosporina.

\section{Material e método}

Este trabalho experimental foi realizado de acordo com as recomendações das Normas Internacionais de Proteção aos Animais e com a Declaração de Helsinki ${ }^{(4,16)}$. Ele foi aprovado pelo Processo 02/01 do Comitê de Ética em Experimentação Animal da Universidade Federal de Minas Gerais (Cetea/UFMG).

O presente estudo foi conduzido em 12 coelhas (oryctogalus cuniculus) das raças Nova Zelândia Branca $(n=6)$ e Califórnia $(n=6)$. Os animais eram provenientes do Biotério Central da Escola de Veterinária da UFMG, onde ficavam mantidos em gaiolas individuais, recebendo alimentação apropriada e permanecendo em adaptação e observação por 20 dias. Todos os procedimentos foram feitos nas dependências do Laboratório de Cirurgia Experimental do Departamento de Cirurgia da Faculdade de Medicina da UFMG, obedecendo às normas técnicas de assepsia e anti-sepsia.

No início do experimento, todos os animais estavam sexualmente maduros, pesando entre 2.300 e 2.700 gramas. Eles foram distribuídos em dois grupos. O grupo $1(n=4)$, de controle, submetido apenas a laparotomia; e o grupo 2 $(n=8)$, a transplante ovariano ortotópico.

No pré-operatório, as coelhas do grupo 2 foram mantidas em jejum de 12 horas para sólidos e líquidos. Uma hora antes do procedimento cirúrgico, todos os animais foram pesados e receberam soluções de ciclosporina $(10 \mathrm{mg} / \mathrm{kg})$ e de cefadroxila $(50 \mathrm{mg} / \mathrm{kg})$. Ambas as substâncias foram dissolvidas em $10 \mathrm{ml}$ de leite e administradas através de cateter orogástrico $\mathrm{n}^{\mathrm{0}} 12 \mathrm{Fr}$. A anestesia foi induzida com injeção intramuscular de cloridrato de quetamina, na dose de $1 \mathrm{~g} / \mathrm{kg}$.

O transplante ocorreu entre pares de coelhas, uma Califórnia e outra Nova Zelândia Branca, que foram operadas simultaneamente. Após a laparotomia mediana infra-umbilical, realizou-se, cuidadosamente, a ooforectomia total bilateral para a preservação do segmento tubário adjacente. Os ovários foram trocados entre essas duas raças de coelhas. Em um lado, transplantou-se o ovário íntegro e, no outro, fatiado em três secções. Eles foram fixados, ortotopicamente, com um ponto de fio de náilon 5-0, sem anastomose vascular. A cavidade abdominal foi fechada em dois planos, com sutura contínua, utilizando-se o fio de náilon 3-0.

Após o ato cirúrgico, as coelhas receberam água e ração Ad Libitum. Durante os três primeiros dias pós-operatórios, os animais do grupo 2 receberam solução de cefadroxila, na 
dose de $50 \mathrm{mg} / \mathrm{kg}$, através de cateter orogástrico. As coelhas receberam diariamente, durante seis meses, $10 \mathrm{mg} / \mathrm{kg}$ de ciclosporina dissolvida em $10 \mathrm{ml}$ de leite, através de cateter orogástrico $\mathrm{n}^{\mathrm{0}} 12 \mathrm{Fr}$.

Decorrido o prazo de acompanhamento, foram colhidos, em ambos os grupos, $2 \mathrm{ml}$ de sangue da veia femoral para as dosagens hormonais de estradiol, progesterona, hormônio foliculoestimulante (FSH) e hormônio luteinizante (LH). As amostras sangüíneas foram rotineiramente processadas em aparelhagem específica. A quantificação hormonal seguiu os métodos de radioimunoensaio para os hormônios gonadais e de imunofluorimetria para os hormônios hipofisários.

Após a coleta, todos os animais foram mortos com dose inalatória letal de éter. Através de uma laparotomia mediana, a cavidade abdominal e seus órgãos foram cuidadosamente estudados. Retiraram-se útero, ovários e tubas uterinas. Após a fixação dos fragmentos em solução de Bouin, eles foram processados para histologia. Secções de 5 micrômetros $(\mu \mathrm{m})$ de espessura foram montadas em lâmina e coradas com hematoxilina e eosina.

Os resultados foram comparados através dos testes $t$ de Student e qui-quadrado com correção de Yates para pequenas amostras. As diferenças foram consideradas significativas para valores correspondentes a $p<0,05$.

Antes do início deste trabalho, em estudo piloto, verificou-se a influência da ciclosporina na manutenção da vitalidade dos ovários transplantados, adotando-se o mesmo método descrito acima. Essa experiência foi realizada em oito coelhas, distribuídas em duplas e submetidas a transplante ovariano homógeno e análise histológica da vitalidade ovárica, em períodos de sete, 14, 21 e 28 dias, sem o imunossupressor.

\section{Resultados}

Todos os animais recuperaram-se espontaneamente das cirurgias e sobreviveram durante os nove meses do experimento, sem intercorrências.

A Tabela mostra os valores hormonais de ambos os grupos, obtidos no final do experimento. Observou-se a presença de hormônios ovarianos em todas as coelhas transplantadas. Os valores hormonais de ambos os grupos mantiveram-se semelhantes, exceto o estradiol, que foi mais elevado no grupo $2(p<0,05)$. Não houve diferença quanto aos níveis hormonais entre as duas raças de coelhas estudadas.
Na segunda laparotomia, a cavidade abdominal do grupo 1 manteve-se com aspecto normal. $\mathrm{O}$ exame macroscópico dos órgãos reprodutores do grupo 2 mostrou ovários implantados, com preservação de sua parte externa e ausência de fibrose ou reações aparentes ao fio cirúrgico em todas as coelhas. Os úteros e as tubas de seis coelhas não apresentaram alterações anatômicas aparentes (Figura 1). Em duas delas, uma Nova Zelândia Branca e outra Califórnia, houve aderências entre a tuba e o ovário, assim como entre este último e as alças intestinais adjacentes.

Através do estudo histológico, verificou-se que os ovários, tanto dos animais controle quanto dos transplantados, estiveram preservados, não havendo disparidades entre esses grupos. Também não foram encontradas diferenças entre os ovários implantados íntegros (Figura 2A) e fatiados (Figura 2B). A viabilidade ovariana foi confirmada pela presença de angiogênese satisfatória, de vários folículos em diferentes estádios de maturação e de corpos lúteos e cistos foliculares em proporções variáveis. Não foram identificados sinais de isquemia ou necrose. Em uma coelha Nova Zelândia Branca, identificaram hemorragia multifocal junto à cápsula e calcificação subcapsular em um dos ovários.

A histologia tubária das coelhas do grupo 1 foi normal, com microvilosidades bem desenvolvidas, trofismo preservado e ausência de sinais inflamatórios ou degenerativos. No grupo 2, em um dos animais, encontrou-se foco de infiltrado mononuclear na mesossalpinge e hipotrofia tubária. Uma outra coelha apresentou reação do tipo corpo estranho na mesossalpinge, além de salpingite crônica discreta e hidrossalpinge. Os demais apresentaram histoarquitetura tubária conservada (Figura 3).

A histoarquitetura uterina de todas as coelhas foi mantida. $\mathrm{O}$ endométrio evidenciou diversas etapas de prolife-

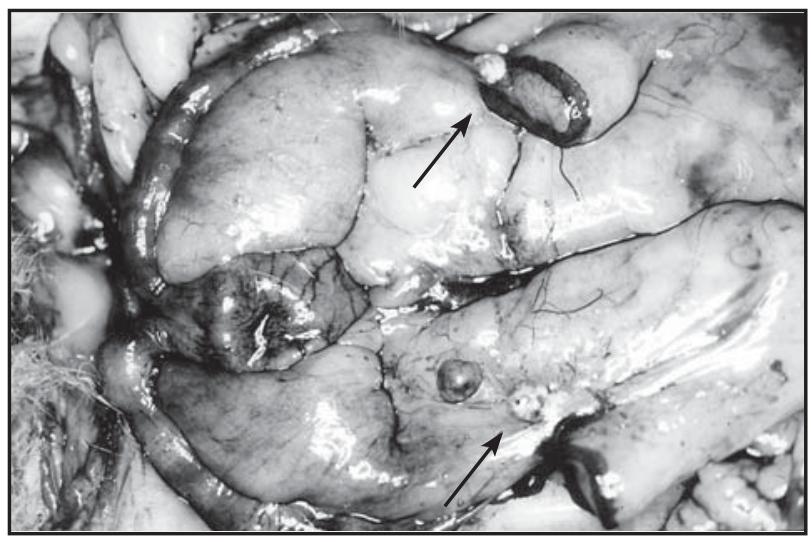

Figura 1 - Visão macroscópica dos órgãos reprodutores de coelha transplantados (grupo 2) na segunda laparotomia. Observa-se a integridade anatômica dos ovários (setas), do útero e da tuba uterina 


\section{Valores hormonais dosados nas coelhas controle e nas submetidas a transplante ovariano}

Tabela ortotópico

\begin{tabular}{lcccc}
\hline Grupo - Coelha & $\begin{array}{c}\text { Estradiol } \\
(\mathrm{pg} / \mathrm{ml})\end{array}$ & $\begin{array}{c}\text { Progesterona } \\
(\mathrm{pg} / \mathrm{ml})\end{array}$ & $\begin{array}{c}\text { FSH } \\
(\mathrm{UI} / \mathrm{l})\end{array}$ & $\begin{array}{c}\text { LH } \\
(\mathrm{UI} / \mathrm{l})\end{array}$ \\
$\mathrm{G} 1-1$ & 1.200 & 106.200 & 0,1 & 0,1 \\
$\mathrm{G} 1-2$ & 2.750 & 105.300 & 0,1 & 0,2 \\
$\mathrm{G} 1-3$ & 2.910 & 105.400 & 0,1 & 0,3 \\
$\mathrm{G} 1-4$ & 106.000 & 0,2 & 0,1 \\
$\mathrm{G} 2-1$ & 3.200 & 103.700 & 0,1 & 0,2 \\
$\mathrm{G} 2-2$ & 3.070 & 99.300 & 0,2 & 0,1 \\
$\mathrm{G} 2-3$ & 4.090 & 105.000 & 0,1 & 0,3 \\
$\mathrm{G} 2-4$ & 101.400 & 0,1 & 0,1 \\
$\mathrm{G} 2-5$ & 105.800 & 0,1 & 0,1 \\
G2 -6 & 6.340 & 103.000 & 0,1 & 0,2 \\
G2 -7 & 5.900 & 105.000 & 0,1 & 0,2 \\
G2 -8 & 5.100 & 106.500 & 0,2 & 0,1 \\
Média G1 & 3.120 & 105.725 & 0,125 & 0,175 \\
Média G2 & 3.560 & 103.713 & 0,125 & 0,162 \\
\hline
\end{tabular}

G1 = grupo 1 (controle); G2 = grupo 2 (transplante ovariano); FSH = hormônio folículo-estimulante; LH = hormônio luteinizante.

*Diferentes entre si para $\mathrm{p}<0,05$ (teste $t$ de Student).

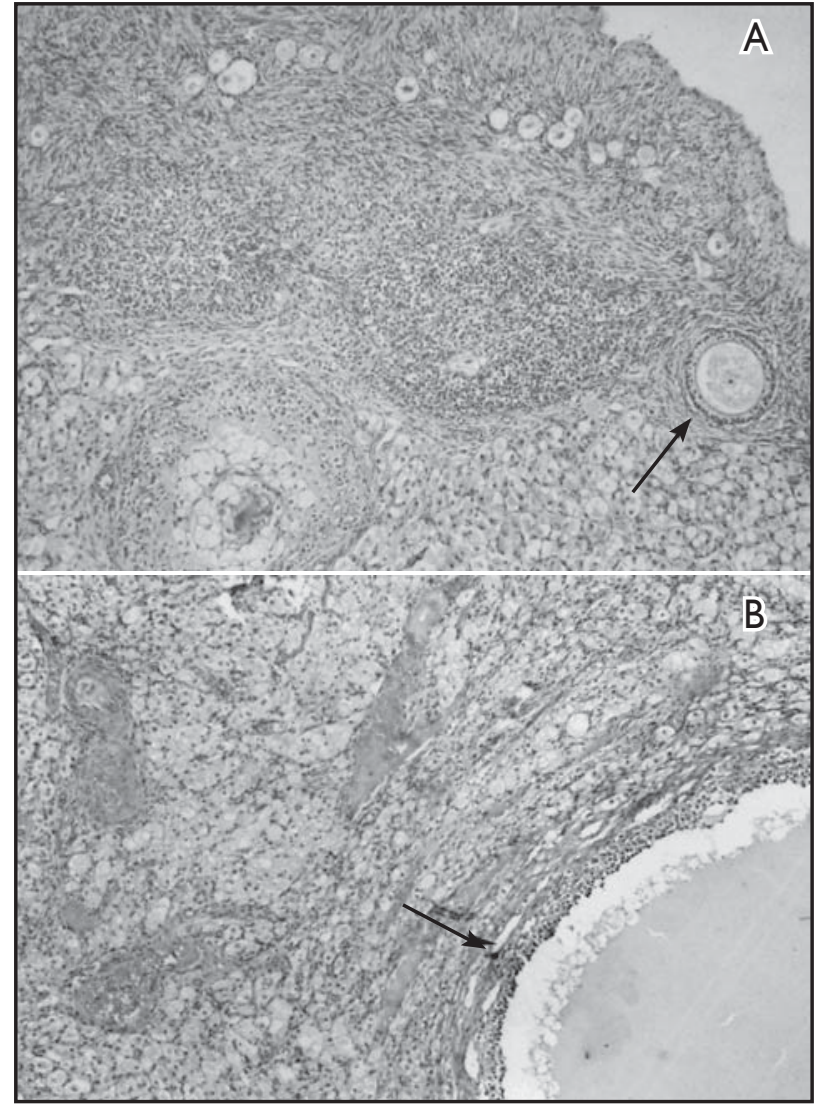

Figura 2 - Histoarquitetura dos transplantes ovarianos. Ambos os cortes mostram preservação das células ovarianas luteínicas (setas) e vascularização satisfatória, bem como ausência de necrose ou degeneração. Hematoxilina e eosina. A: Ovário íntegro (40x); B: ovário fatiado (100x) ração, compatíveis com as fases do ciclo estral, indicando adequada produção hormonal.

Com relação ao estudo piloto, aos sete dias, não se perceberam alterações morfológicas nos ovários. Aos 14 dias, houve sinais inflamatórios e de isquemia ovariana. Aos 21 dias, os ovários apresentavam extensas áreas de necrose, ocorrendo a substituição do parênquima por fibrose. Aos 28 dias, não encontramos os ovários, apenas tecido fibroso local.

\section{Discussão}

O transplante de ovários em pacientes com falência ovariana é análogo ao de ilhotas de Langerhans, nos casos de diabetes melito ou de neurônios dopaminérgicos na doença de Parkinson. Todas essas entidades patológicas podem ser tratadas com suplementação farmacológica. Entretanto, a terapia tecidual tem a vantagem de manter a atividade fisiológica das secreções hormonal e neuronal(3). As possibilidades e vantagens desta terapêutica estão sendo gradualmente conhecidas.

O presente estudo mostra que os ovários sem anastomose vascular transplantados em coelhas são viáveis e preservam sua função endócrina em todos os casos. Não foram detectadas adversidades decorrentes da falta de 


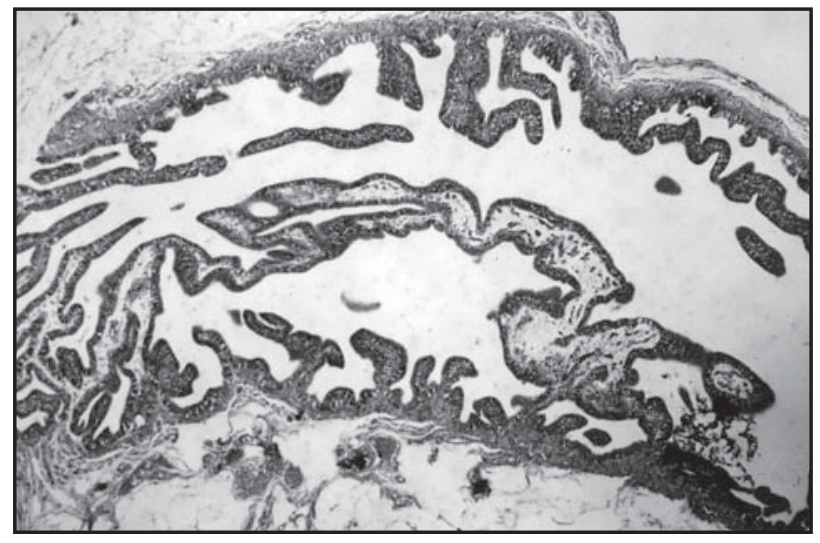

Figura 3 - Histoarquitetura tubária de coelhas transplantadas (grupo 2). Identificam-se microvilosidades bem desenvolvidas e ausência de sinais inflamatórios ou degenerativos. Hematoxilina e eosina (40x)

vascularização inicial, pois nenhum dos animais apresentou sinais de isquemia ovariana. Esses achados contradizem alguns autores que consideram fundamental a revascularização cirúrgica dos enxertos dos ovários ${ }^{(3,13)}$. Entretanto os resultados deste trabalho estão de acordo com o que alguns estudos verificaram. Segundo estes, a anastomose do pedículo vascular é desnecessária para a manutenção da viabilidade e da função ovariana. A intensa neovascularização que se forma em torno do ovário parece ser suficiente para conservar sua vitalidade ${ }^{(20,25)}$. Isso porque 0 tecido ovariano é uma rica fonte de fatores angiogênicos, que estimulam a rápida migração de células endoteliais nos casos de transplantes, o que leva ao restabelecimento da circulação sangüínea(3,14).

A vitalidade dos ovários transplantados também pode ser confirmada pela manutenção de sua função endócrina, mediante a presença de estradiol e progesterona circulantes, bem como suas interações com os hormônios hipofisários (FSH e LH). Embora as concentrações dos demais hormônios fossem semelhantes em ambos os grupos, os animais transplantados apresentaram maiores concentrações de estradiol. Uma possível explicação seria a coincidência de todas as coelhas do grupo 1 estarem na fase pré-ovulatória no momento da coleta de sangue, período em que a concentração de estradiol seria normalmente mais baixa. Contudo não encontramos nos dados do presente trabalho, nem na literatura, outras informações que pudessem esclarecer melhor este achado.

Quanto à viabilidade histológica, conclui-se que a administração diária de ciclosporina foi essencial para a manutenção da vitalidade dos ovários transplantados.
No estudo piloto, quanto maior foi o tempo de supressão deste fármaco, maiores foram os sinais de rejeição do transplante, com progressiva degeneração e fibrose no local de implantação ovariana. Notaram-se também alterações macroscópicas importantes nos demais órgãos reprodutores, como atrofia uterina e tubária, provavelmente pela ausência de estímulos dos hormônios gonadais. Entretanto, em presença de ciclosporina, a viabilidade ovariana também pode ser confirmada pelo estudo histológico, com ausência de sinais indicativos de rejeição tanto no ovário quanto na trama vascular periovariana. Além disso, não houve evidência histológica ou funcional de que o medicamento tivesse ocasionado alterações de formação folicular e nos fenômenos ovulatórios. Apesar de alguns autores terem indicado doses maiores de ciclosporina $(15 \mathrm{mg} / \mathrm{kg} \text { ao dia) })^{(7-9)}$, a dose de $10 \mathrm{mg} / \mathrm{kg}$ ao dia, utilizada no presente estudo, segundo nossa linha de pesquisa(17), manteve a vitalidade e a função ovariana, sem os possíveis inconvenientes decorrentes da imunossupressão em altas doses. Também não foi constatado o efeito inibitório da ciclosporina sobre a ovulação, embora outros autores afirmem que esse fármaco tem propriedades anovulatórias ${ }^{(8)}$. Apesar desses achados, não encontramos fundamento na literatura para uma explicação adequada desse fenômeno. Os relatos de vários autores ainda são controversos.

\section{Conclusões}

Os resultados do presente trabalho mostram que é possível preservar a função endócrina ovariana após a ooforectomia por meio de transplante de ovário homógeno. A ciclosporina, como imunossupressor, é eficaz e imprescindível para manter a vitalidade e a função dos ovários transplantados.

\section{Agradecimentos}

Agradecemos ao patologista clínico, dr. Décio de Vasconcellos Filho, pela gentileza nas dosagens hormonais. Somos gratos também aos laboratórios Natures Plus-Sigma Pharma e Novartis (São Paulo, Brasil), que forneceram a ciclosporina para o presente estudo. Agradecemos ainda ao Conselho Nacional de Desenvolvimento Científico e Tecnológico (CNPq) e à Fundação de Amparo à Pesquisa do Estado de Minas Gerais (Fapemig) pelos auxílios financeiros que permitiram a realização deste trabalho. 


\section{Referências}

I. AUBARD, Y. et al. Conservation of the follicular population in irradiated by the cryopreservation and orthotopic autografting ovarian tissue. Eur J Obstet Gynecol Reprod Biol, v. 79, p. 83-7, 1998.

2. BABER, R:;ADBELLA, H.; STUDD, F.The premature menopause. Prog Obstet Gynaecol, v. 9, p. 209-26, 1991.

3. CALLEJO, J. et al. Heterotopic ovarian transplantation without vascular pedicle in syngenic Lewis rat. Fertil Steril, v. 72, p. 5।3-7, 1999.

4. COOPER, J. E. Ethics and laboratory animals. Vet Rec, v. II6, p. 594-5, 1985.

5. CORLETA, H. V. E. et al. Subcutaneous autologous ovarian transplantation in Wistar rats maintains hormone secretion. Fertil Steril, v. 70, p. 16-9, 1998.

6. CORNIER, E.; SIBELLA, P.; CHATELET, F. Études histologiques et devenir fonctionnel des greffes de trompe et d'ovaire chez la rate. J Gynecol Obstet Biol Reprod, v. 14, p. 567-73, 1985.

7. ESQUIFINO,A. I. et al. Effects of cyclosporine on ovarian function in sham-operated and pituitary-grafted young female rats. Soc Exp Biol Med, v. 208, p. 397-403, 1995.

8. GALLAGHER,A. C.; CHAMBERS,T.J:;OBIAS,J. H. Distinct effects of ovarian transplantation and exogenous I7B estradiol on cancellous bone of osteopenic ovariectomized rats. Eur J Endocrinol, v. I33, p. 483-8, 1995.

9. HARP, R. et al. Cryopreservation of murine ovarian tissue. Cryobiology, v. 31, p. 336-43, 1994.

10. LARA, H. E. et al. Functional recovery of the developing rat ovary after transplantation. Endocrinology, v. 129, p. 1849 60, 1991.

I I. MACKIE, E. J.; RADFORD, J. A.; SHALET, S. M. Gonadal function following chemotherapy for childhood Hodgkin's disease. Med Pediatr Oncol, v. 27, p. 74-8, 1996.

12. MARMOR, D. Fertility after antimitotic treatments. Bull Cancer, v. 84, p. 764-9, 1994.

13. NAMBA, Y. et al. Suppressive effect of perinatal tests on the differentiation of fetal ovaries transplanted into adult males in the rat. J Anat, v. 191, p. 31-8, 1997.
14. NISOLLE, M. et al. Histologic and ultrastructural evaluation of fresh and frozen-thawed human ovarian xenografts in nude mice. J Fertil Steril, v. 74, p. 122-9, 2000.

15. PARKS, J. E.; RUFFING, N. A. Factors affecting low temperature survival of mammalian oocytes. Theriogenology, v. 37 . p. 59-72, 1992.

16. PETROIANU,A. Pesquisa experimental. In PETROIANU,A. Ética, moral e deontologia médicas. I. ed. Rio de Janeiro: Ganabara Koogan, 2000. p. $185-90$.

17. PETROIANU, A. et al. Natural pregnancy in rabbit that underwent oophorectomy and orthotopic allogeneic or autologous ovarian transplantation. Fertil Steril, v. 77, p. 1289-99, 2002.

18. RAMÍREZ, G. et al. Cyclosporine-induced aalterations in the hypothalamic hypophyseal gonadal axis transplant patients. Nephron, v. 58, p. 27-32, 1991.

19. RESENDE, C.A. L.; GOBBI, H.; GEBER, S.Aspectos embriológicos, histológicos, anatômicos e fisiológicos dos ovários. In: $\mathrm{CORONHO}$, V. et al. Tratado de endocrinologia e cirurgia endócrina. I. ed. Rio de Janeiro: Guanabara Koogan; 200 I. p. 1060-95.

20. RONE, J. D.; HALVORSON, L. M.; GOODMAN, A. L. Ovarian angiogenesis in rabbits.J Reprod Fértil, v. 97, p. 359-65, 1993.

21.SEETHALAKSHMI, L. et al. Cyclosporine, its effects on testicular function and fertility in the prepubertal rat. J Androl, v. I I, p. 17-24, 1990.

22. SIMÕES, P. M.; MACHADO, J. A. Complicações das cirurgias sobre os ovários. In: CORONHO, V. et al. Tratado de Endocrinologia e Cirurgia Endócrina. I. ed. Rio de Janeiro: Guanabara Koogan, 200 I. p. I I26-8.

23. SPEROFF, T. et al. A risk-benefit analysis of elective bilateral oophorectomy. Am J Obstet Gynecol, v. I64, p. 165-74, 199 I.

24. VON EYE, C. H. et al. Subcutaneous autologous ovarian transplantation in wistar rats maintains hormone secretion. Fertil Steril, v. 70, p. 16-9, 1998.

25.WEISSMAN,A. et al. Preliminary experience with subcutaneous human ovarian cortex transplantation in the NOD-SCID mouse. Biol Reprod, v. 60, p. 1462-7, 1999.
Endereço para correspondência

Andy Petroianu

Av. Afonso Pena 1.626/1.901

CEP 30130-005 - Belo Horizonte-MG

Telefax: (31) 3274-7744

e-mail: petroian@medicina.ufmg.br 